\title{
Study of Ceramic and Hybrid Coatings Produced by the Sol-Gel Method for Corrosion Protection
}

\author{
G. Carbajal-de la Torre ${ }^{1}$, M.A. Espinosa-Medina ${ }^{2}$, A. Martinez-Villafañe ${ }^{3}$, J.G. Gonzalez-Rodriguez ${ }^{4}$ \\ and V.M. Castaño ${ }^{*}$ \\ ${ }^{I}$ Facultad de Ingeniería Mecánica, UMSNH, Santiago Tapia 403 Col. Centro, C.P. 58098 Morelia, Michoacán, México \\ ${ }^{2}$ Instituto Mexicano del Petróleo, Eje Central Lázaro Cárdenas Norte \#152, San Bartolo Atepehuacan, 07730, México, \\ $D F$, México \\ ${ }^{3}$ Centro de Investigación en Materiales Avanzados, CIMAV, Miguel de Cervantes 120, Complejo Ind. Chihuahua, \\ Chihuahua, Chih., México \\ ${ }^{4}$ U.A.E.M - CIICAp, Av. Universidad 1001, C.P. 62210, Col. Chamilpa, Cuernavaca, Morelos, México \\ ${ }^{5}$ Centro de Física Aplicada y Tecnología Avanzada, CFATA, UNAM. Apartado Postal 1-1010. Santiago de Querétaro, \\ Qro., 76000, México
}

\begin{abstract}
Silica based ceramic oxides and hybrid coatings were developed using 3-(trimethoxysilyl) propylmethacrylate (TMSPM), methylmethacrylate (MMA) as the organic phase with different fractions of tetraethoxysilane (TEOS) and aluminium isopropoxide as the inorganic phase using sol-gel process which were deposited onto 316 stainless steel substrate by dip-coating technique, followed by a sintering step. Characterization of the obtained coatings was carried out by scanning electron microscopy to determine the topographical features of the coatings. Furthermore, the coatings were analyzed in this manner after the corrosion tests. Analyses of corrosion resistance for coated and uncoated samples were performed in $\mathrm{SO}_{4}^{2-}$ and $\mathrm{Cl}^{-}$solutions. The influence of the sol characteristic and composition, as well as the behaviour of the coatings during the corrosion tests were reported. The results show that coatings prevent corrosion in an acid environment, and the ceramic coating developed best resistance corrosion under those media.
\end{abstract}

Keywords: Thin films, ceramic mix-oxide, hybrid, coatings, sol-gel, dip-coating, corrosion, stainless steel, acid medium, electrochemical tests.

\section{INTRODUCTION}

One of the most interesting applications of the sol-gel method is the deposition of thin oxide layer on glass, ceramic or metal substrates. In the literature, there are many examples showing the versatility and the simplicity of this method to produce coatings for many different purposes $[1$, 2]. The coatings like hybrid mix-up improve the chemical and physical properties of the metal surfaces relative to corrosion, friction and wear performance without altering the original properties such as strength and toughness of the substrate [3]. During sol-gel thin film formation via dipping, inorganic or metal organic sol is deposited on the substrate surface by a complex steady-state process combining gravitational draining, solvent evaporation and continued condensation reactions $[4,5]$.

The properties of the hybrids are not just the direct addition of the individual contributions from inorganic and organic components. The use of synergistic effects by combining both components can lead to the innovation of multifunctional materials. A wide versatility in the design of the inorganic-organic hybrids provides various applications

*Address correspondence to this author at the Centro de Física Aplicada y Tecnología Avanzada, CFATA, UNAM. Apartado Postal 1-1010. Santiago de Querétaro, Qro., 76000, México; E-mail: castano@fata.unam.mx of these materials in the fields of optics, electronics, mechanics, biology and others [6]. The inorganic component in the hybrid films has reinforced the organic component enhancing hardness and consequently more abrasion resistant films are achieved compared to the pure PMMAfilms [7]. The presence of organic components turns the gel network into a more flexible and less prone to crack film during further heat-treatment. Moreover, the impregnation of open pores by organic materials can reduce the coating porosity producing a better diffusion barrier [8].

It is possible to hybridize ceramics and polymers using a relatively new low-temperature method for ceramic processing. This sol-gel process involves the formation of an inorganic glass from solution and yields a high-purity homogeneous ceramic material $[9,10]$. One successful approach to hybridization has been to use the sol-gel process to polymerize metal alkoxides in organic polymer matrices [11-17]. In addition, this process can be used to prepare an inorganic-organic hybrid coating through the in situ polycondensation of a metal alkoxide in an inorganic polymer matrix $[18,19]$.

The coatings of metallic surfaces by sol-gel films have been proposed as a useful way to protect against acid corrosion [20]. The barrier coated via sol-gel process consists of the preparation of a solution (sol), from which the 
gel is obtained and applied by several methods to protect the surfaces [21-26]. The deposition of these thin films can offer some advantages in devices, particularly in the case of integrated hybrid systems. Homogeneous thin films could be prepared by dipping process using alkoxides. The metal alkoxide method offers many advantages such as: high purity, low-temperature processing and controllability of the composition $[22,23,27]$. The dipping process is one of the deposition methods involving liquid films [28, 29]. Sol-gel dip-coating has been used to develop corrosion resistance on structural metallic components, like low carbon steels [22, 23] showing good performance in corrosion protection into environments of chemical industry. In industrial applications sulphuric acid is one of top products of the chemical industry like: fertilizer manufacturing, oil refining wastewater processing, and chemical synthesis of many kinds [30]. Additionally, it is a constituent of acid rain which is formed by atmospheric oxidation of sulphur dioxide (from combustion oil process, as an example) in the presence of water, i.e., oxidation of sulphurous acid). In this sense, chlorine acid solution can be present in the processes of chemical intermediate in other chemical production (of hydrochloric acid), hydrochlorination of rubber, production of vinyl and alkyl chlorides, etc. All those industrial acid conditions are the promoters of the structural material corrosion, and are necessary a form of material protection or corrosion inhibition; which can be obtained by the surface modification by sol-gel coatings.

In this work, the results of a systematic corrosion study by electrochemical dynamic-polarization tests of sol-gel coatings of ceramic mix-oxide and hybrid coatings deposited on stainless steel 316 by dip coating technique in acid environments $\left(\mathrm{H}_{2} \mathrm{SO}_{4}\right.$ and $\mathrm{HCl}$ solutions at $1.0 \mathrm{M}$ and $0.1 \mathrm{M}$ concentrations) are presented. The results were complemented by SEM characterization.

\section{METHODOLOGY}

A simple method to obtain organic-inorganic hybrids is by mixing an organic polymer with a silicon alkoxide such as tetraethoxysilane (TEOS) as the silicate source; followed by sol-gel reaction involving hydrolysis and polycondensation of TEOS [29].

\section{Materials}

Samples of stainless steels 316 were used as substrate in the metal/coating system. Tetraethoxysilane (TEOS, 99\% Aldrich) was used as the silica source. 3-(trimethoxysilyl) propylmethacrylate (TMSPM, 98\% Aldrich) and methylmethacrylate (MMA, 99\% Aldrich), were used as the polymer component. $\mathrm{HCl}$ was used as the catalyst is $(2,2$, Azobisisobutyronytrile) for hydrolysis. The metal alkoxide of aluminium (aluminium isopropoxide, AIP, 98\% Aldrich) was used for preparing the ceramic coating. The chemical composition of stainless steel 316 (SS 316) used as coating substrate is: $\mathrm{Fe}$ (balance), $<0.03 \% \mathrm{C}, 16-18.5 \% \mathrm{Cr}, 10-14 \%$ $\mathrm{Ni}, 2-3 \% \mathrm{Mo},<2 \% \mathrm{Mn},<1 \% \mathrm{Si},<0.045 \% \mathrm{P},<0.03 \% \mathrm{~S}$. The substrate was selected due to its corrosion resistance known characteristics, in order to minimize substrate signals and differentiated the coating behaviour. Pieces of $40 \times 20 \mathrm{~mm}^{2}$ from $1.0 \mathrm{~mm}$ of thickness foil were cut and surface finished by polished, cleaned and degreased with isopropylic alcohol and air-dried.

\section{Sol Preparation}

Preparation of $M_{1}$ sol: The silica-sol was prepared by acid-catalysed hydrolysis of tetraethylorthosilicate (TEOS) in ethanol and in the presence of $\mathrm{HCl}$. This sol was reflux under heating for 3 hours. Next, $0.2 \mathrm{~g}$ of AIP (aluminium isopropoxide) dissolved in ethanol was added. The resultant mixture was heated to $76^{\circ} \mathrm{C}$ for 3 hours under reflux. The molar ratio $\mathrm{Si}: \mathrm{Al}$ was $2: 1$.

Preparation of $\boldsymbol{C}_{\boldsymbol{I}}$ sol: First, the copolymerization of MMA and TMSPM is carried out in nitrogen atmosphere and using AIBN (2,2' Azo Bis Iso Butilonitrilo) as an initiator at $70^{\circ} \mathrm{C}$ during 60 minutes. The obtained liquid is diluted in methanol, and TEOS is slowly added in the appropriate quantity. For the hydrolysis reaction at ambient temperature, acid water is added $(0.15 \mathrm{~N} \mathrm{HCl})$, using an equivalent of water for alkoxile group. Finally, the previously dissolved AIP is added in hot ethanol $\left(80^{\circ} \mathrm{C}\right)$ and it is allowed that the formation reaction is made of the mixed oxide $\mathrm{SiO}_{2}-\mathrm{Al}_{2} \mathrm{O}_{3}$ to ambient temperature for 3 hours. The molar ratio $\mathrm{Si}: \mathrm{Al}$ is $2: 1$.

\section{Coating Procedure}

Steel substrates $(10 \times 10 \times 0.1 \mathrm{~cm})$ were polished, cleaned and degreased with isopropylic alcohol and air-dried. The two prepared sol solutions were used to deposit the sol onto the substrates by dip-coating technique. Each substrate was dipped into the sol at an immersion speed of $20 \mathrm{~cm} / \mathrm{min}$ for 5 minutes, and then withdrawn at the same speed previously mentioned. After deposition, the coated samples were airdried and heat treated at $600^{\circ} \mathrm{C}$ for 2 hours by heating rate of $2^{\circ} \mathrm{C} / \mathrm{min}$, as before reported [31]. Similarly, the hybrid coatings were dried at room temperature and then heat treated at $200^{\circ} \mathrm{C}$. The SS 316 alloy used as substrate, is characterized as extra-low-carbon and is stabilized grade stainless steel (with 0.030 wt. \% of carbon) [32], and this material is required to be heat treated at 650 to $675^{\circ} \mathrm{C}$ in order to be sensitized, although, the most commonly used sensitizing treatment is 1 hour at $675^{\circ} \mathrm{C}$. However, for this stainless steel alloy, the sensitizing appears after the 50 hours at $650^{\circ} \mathrm{C}$ [33]. Because of the heat treatment minimum changes were expected in the substrate.

\section{Corrosion Analysis}

The corrosion resistance analyzes of the coated samples which were carried out by the electrochemical polarization technique using a computerized potentiostate (ACM Instruments). The electrochemical cell consisted of a saturated calomel electrode (SCE) used as a reference electrode, a graphite foil used as auxiliary electrode and the work electrode was each coated sample. Work electrode area exposed to the electrolyte was $1.0 \mathrm{~cm}^{2}$, for each specimen, the rest of sample surface was insulated with epoxy paint. The potentiodynamic measurements were initiated at -200 $\mathrm{mV}$ and ended at $1500 \mathrm{mV}$ from the open circuit potential with a scanning rate of $1 \mathrm{mV} / \mathrm{s}$. The electrolyte solutions were $\mathrm{H}_{2} \mathrm{SO}_{4}$ and $\mathrm{HCl}$ in both 1.0 and $0.1 \mathrm{M}$ concentrations at room temperature. In addition, Scanning electronic microscopy (SEM, JEOL JSM5800 LV) was used to study topographical features and the homogeneity of surface analysis. 


\section{RESULTS AND DISCUSSION}

Fig. (1) shows an example of the surface morphology of one coating applied onto the substrate; similar morphologies were obtained by all coatings. In this figure the SEM micrograph of the $\mathrm{SiO}_{2}-\mathrm{Al}_{2} \mathrm{O}_{3}$ coating (sample $\mathrm{M}_{1}$ ) obtained by the dip-coating technique followed by the heat treatment (Fig. 1) is shown. SEM micrographs show uniform, homogeneous and crack-free surfaces of sol-gel coatings, which were readily obtained after post-deposition annealing. The morphology of the ceramic coatings showed a completely covered surface, following similar surface topography in accordance with the polished surface texture of the substrate, likewise macrostructural defects or holes were not observed. Similar surface characteristics were obtained for the hybrid coating samples here evaluated, as similar results before were reported [22, 23, 34]. Homogeneity characteristics of coatings are a desired part of the roles of protective layers that consists in mitigate the corrosion into a specific corrosive environment [21]. These coatings have to improve physical barrier with anticorrosive characteristics.

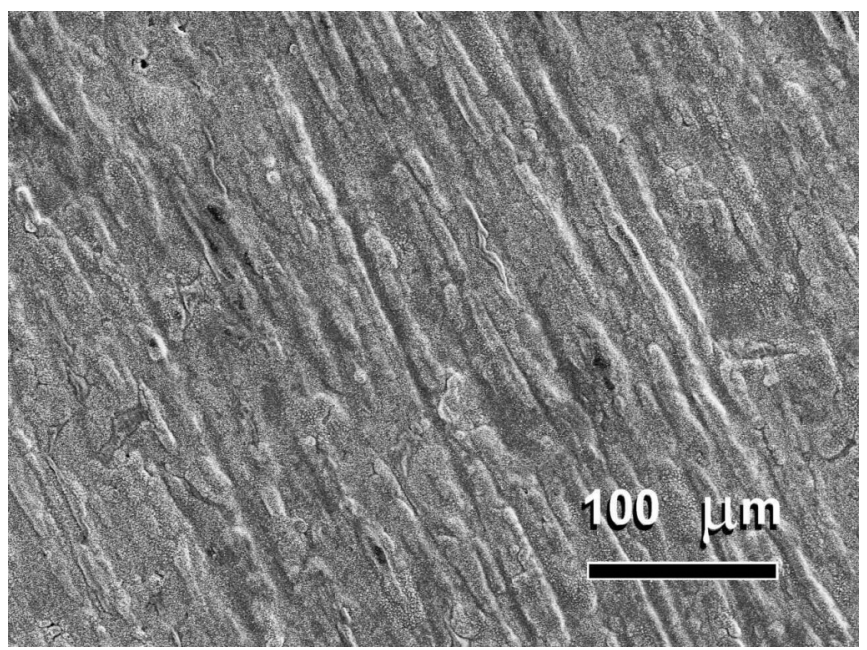

Fig. (1). SEM micrograph of the $M_{1}$ coating obtained by dipcoating technique.

The role of protective films is to avoid or reduce corrosion in an acidic and basic environment [21]. The results of corrosion tests of $\mathrm{M}_{1}$ and $\mathrm{C}_{1}$ coating systems into $\mathrm{H}_{2} \mathrm{SO}_{4}$ medium are shown in Figs. $(2,3)$. Table 1 shows the summary of the electrochemical parameters measured from these results. In the $1.0 \mathrm{M} \mathrm{H}_{2} \mathrm{SO}_{4}$ solution, the $\mathrm{M}_{1}$ coating sample showed a decrease in corrosion current density; $i_{\text {corr }}$, around one order of magnitude (see Table 1). As well, its potential was reached to more positive values around of 600 $\mathrm{mV}$ more positive from the corrosion potential $\left(E_{\text {corr }}\right)$ in reference of the uncoated material. This coated sample showed an anodic behaviour with limited current density in the range of $500 \mathrm{mV}$ over its $E_{\text {corr }}$, before the potential exceeded the breakdown potential. This behaviour was improved by the protective barrier characteristic of the coating, as before reported [23]. However, $\mathrm{C}_{1}$ coating into this solution concentration did not improve a significant change on corrosion resistance, but it showed some characteristics in the anodic current zone. In this way, the $\mathrm{C}_{1}$ coating sample presented two ranges of anodic potential of $200 \mathrm{mV}$ amplitude approximately with an anodic current limit (around $2.7 \times 10^{-3}$ and $8.2 \times 10^{-3} \mathrm{~mA} / \mathrm{cm}^{2}$ respectively); before the point of the breakdown potential was reached.
One of this potential ranges was observed after the activation transition (at $+140 \mathrm{mV}$ of over-potential) and the second was observed at $+400 \mathrm{mV}$ over the $E_{\text {corr }}$. As a comparative result, the uncoated material presented a continuous potential range characterized by a control mechanism of equilibrium in the oxidation and reduction reactions. Also indications of breaking passive film characteristic of stainless steels were observed (curve 1 of Fig. 2). The comparison of the polarization results of behaviour of coatings material versus a self-protective substrate (SS 316) was done in order to evaluate the protective characteristics of those coatings, which could be applied in other non-self-protective structural materials to improve better corrosion resistance behaviour.

Table 1. Summary of the Electrochemical Parameters Measured from Polarization Results in the $\mathrm{H}_{2} \mathrm{SO}_{4}$ Solutions

\begin{tabular}{|c|c|c|c|c|c|}
\hline Sample & Electrolyte & $\begin{array}{c}E_{\text {corr }} \\
(\mathrm{mV})\end{array}$ & $\begin{array}{c}i_{c o r r} \\
\left(\mathbf{m A} / \mathbf{c m}^{2}\right)\end{array}$ & $\begin{array}{c}B a \\
(\mathbf{m V})\end{array}$ & $\begin{array}{c}B c \\
(\mathrm{mV})\end{array}$ \\
\hline uncoated & \multirow{3}{*}{$1 \mathrm{M} \mathrm{H}_{2} \mathrm{SO}_{4}$} & +055 & $3.01 \times 10^{-4}$ & 200 & 150 \\
\hline $\mathrm{M}_{1}$ & & +664 & $4.37 \times 10^{-5}$ & 195 & 121 \\
\hline $\mathrm{C}_{1}$ & & +043 & $7.14 \times 10^{-4}$ & 201 & 151 \\
\hline uncoated & \multirow{3}{*}{$0.1 \mathrm{M} \mathrm{H}_{2} \mathrm{SO}_{4}$} & -332 & $6.81 \times 10^{-3}$ & 550 & 057 \\
\hline $\mathrm{M}_{1}$ & & +468 & $3.85 \times 10^{-5}$ & 140 & 108 \\
\hline $\mathrm{C}_{1}$ & & +079 & $1.73 \times 10^{-4}$ & 113 & 108 \\
\hline
\end{tabular}

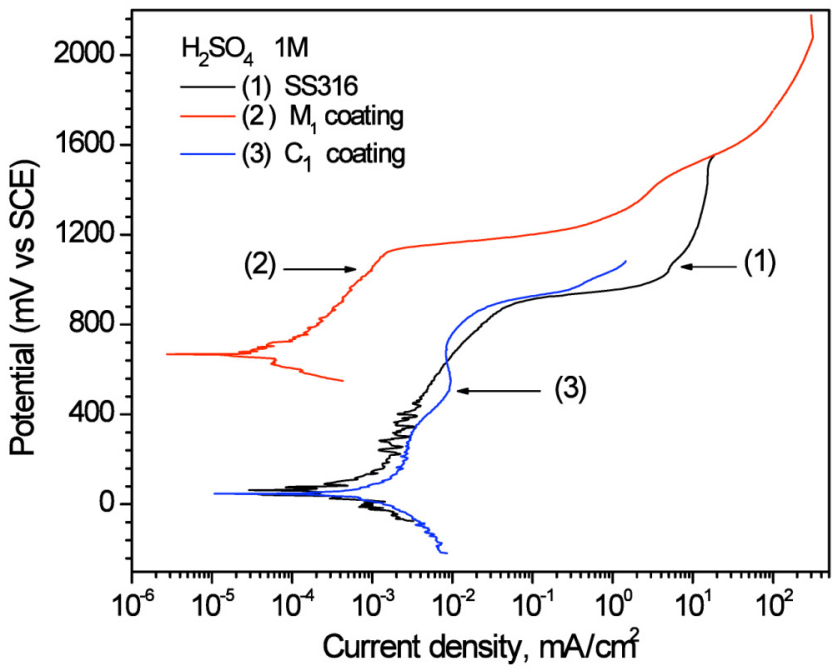

Fig. (2). Potentiodynamic polarization curves of coated SS 316 in $1 \mathrm{M}-\mathrm{H}_{2} \mathrm{SO}_{4}$ solution at $25^{\circ} \mathrm{C}$.

In similar way, the polarization measurements of $\mathrm{C}_{1}$ coating sample into $0.1 \mathrm{M} \mathrm{H}_{2} \mathrm{SO}_{4}$ solution showed better corrosion resistance behaviour than showed into the $1.0 \mathrm{M}$ solution concentrations. It was reflected in a decrease of $i_{c o r r}$ from 0.714 to $0.173 \mu \mathrm{A} / \mathrm{cm}^{2}$ values; and $E_{\text {corr }}$ potentials were without significant changes. Moreover, the $M_{1}$ coating sample presented an improvement in the corrosion resistance in this solution showing values of $i_{\text {corr }}$ in the same order (Table 1) than observed into the $1.0 \mathrm{M}$ solution (Fig. 3). In this way, the $\mathrm{C}_{1}$ coating sample presented an anodic current behaviour limited on a value of $1 \times 10^{-4} \mathrm{~mA} / \mathrm{cm}^{2}$ approximately in the potential range of around $600 \mathrm{mV}$ 
nearby to its $E_{\text {corr }}$ potential. The limited anodic current behaviour, presented by the hybrid-oxide coating, was the characteristic of passive behaviour; and then post-passivation transition behaviour was occurred. This transition was observed at $+700 \mathrm{mV}$ anodic potential $v s$ its $E_{c o r r}$ (arrow $a$; Fig. 3). In this solution the $M_{1}$ coating sample showed activation mechanism behaviour principally, with anodic current density controlled by oxidation and reduction reactions equilibrium. The transition of this behaviour to faster anodic dissolution (controlled by the rate of oxidation reactions) due the increase of over-potential is pointed with the arrow $b$; Fig. (3), and reached around $+953 \mathrm{mV}$ potential values $\left(v s E_{c o r r}\right)$ showing anodic current density values of $0.01 \mathrm{~mA} / \mathrm{cm}^{2}$ approximately. Last current density was similar to be shown by the uncoated alloy, in the anodic curve. At over-potential conditions which $\mathrm{M}_{1}$ coating showed its breakdown transition point, coating layer became to scratch faster and then exposed areas increase; as a result, corrosion current increased. We suggest that point $b$ describes a start of limited current behaviour as response of the contribution capacitance of the metallic interface as an addition of a mechanism of element diffusion of alloy. In addition, the $\mathrm{M}_{1}$ coating sample showed a displacement in the $E_{\text {corr }}$ potential to more positive values showing better corrosion resistance or lower activity, nevertheless the hybrid coating showed the best passive behaviour in a wide potential region.

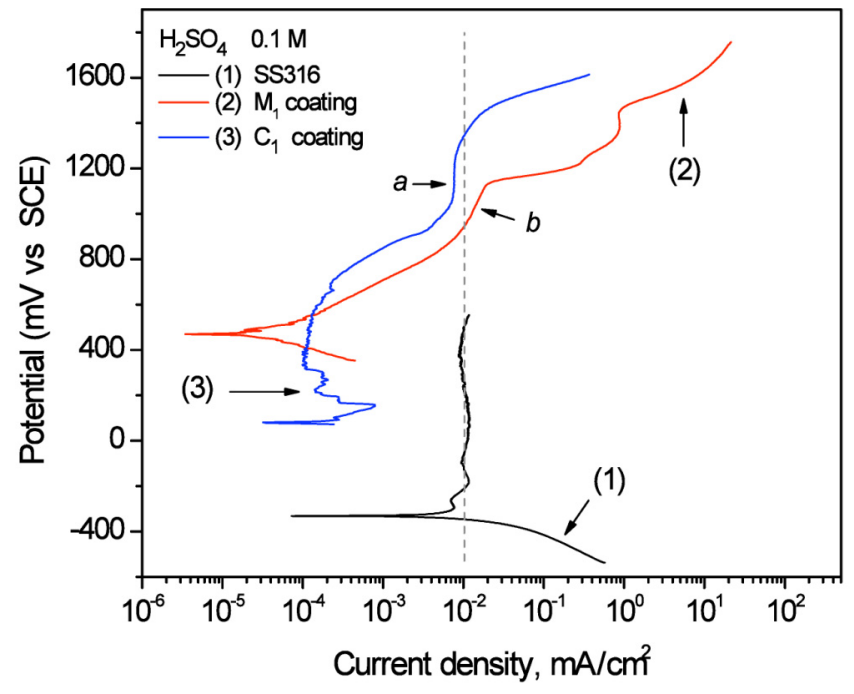

Fig. (3). Potentiodynamic polarization curves of coated SS 316 in $0.1 \mathrm{M} \mathrm{H}_{2} \mathrm{SO}_{4}$ solution at $25^{\circ} \mathrm{C}$.

The results obtained by the potentiodynamic tests of $\mathrm{M}_{1}$ and $\mathrm{C}_{1}$ coatings in $\mathrm{HCl}$ solutions are showed in Figs. $(4,5)$. Table 2 shows the summary of the electrochemical parameters measured from these results. In this solution at 1.0 M, the uncoated stainless steel showed a more negative cell potential and bigger $i_{\text {corr }}$, meaning higher corrosion rate by the Tafel fitting parameters. All the coatings presented improved corrosion resistance at the OCP region. In addition, the more positive $E_{\text {corr }}$ potential was obtained by $\mathrm{M}_{1}$ coating in $0.1 \mathrm{M} \mathrm{HCl}$ solution, while the $E_{\text {corr }}$ of electrolyte/coating interface became more negative as the concentration increase. On the other hand, the $\mathrm{C} 1$ coating had less corrosion current density $\left(i_{\text {corr }}\right)$ than the SS 316 substrate, just a smaller positive displacement of anodic curve, and presented the characteristic of "S" shape curve of stainless steel in this medium [35]. The most important feature of the polarization results was the electrochemical behaviour of coatings systems near the $E_{\text {corr }}$ potential, where the coatings showed good response on corrosion resistance in $\mathrm{HCl}$ environment. Also the $i_{\text {corr }}$ values were smaller than the measured ones from the uncoated material (cf. Table 2). These coatings were produced with a Si:Al $=2: 1$ ratio, besides coating systems with a $\mathrm{Si}: \mathrm{Al}=1: 1$ ratio previously reported [22], showed a good response with a passivation behaviour by the $\mathrm{M}_{1}$ coating system.

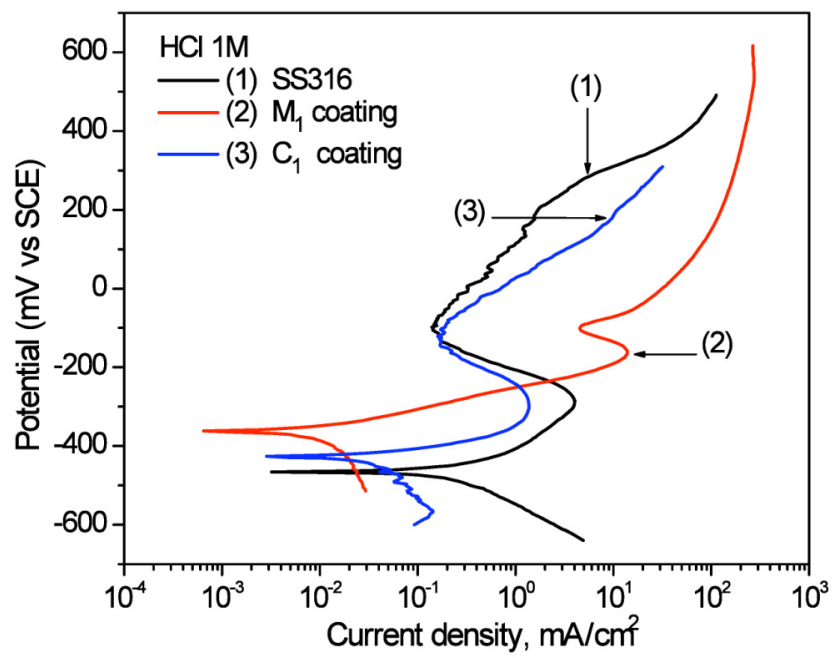

Fig. (4). Potentiodynamic polarization curves obtained in $1.0 \mathrm{M}$ $\mathrm{HCl}$ solution at room temperature for SS 316 and coating systems.

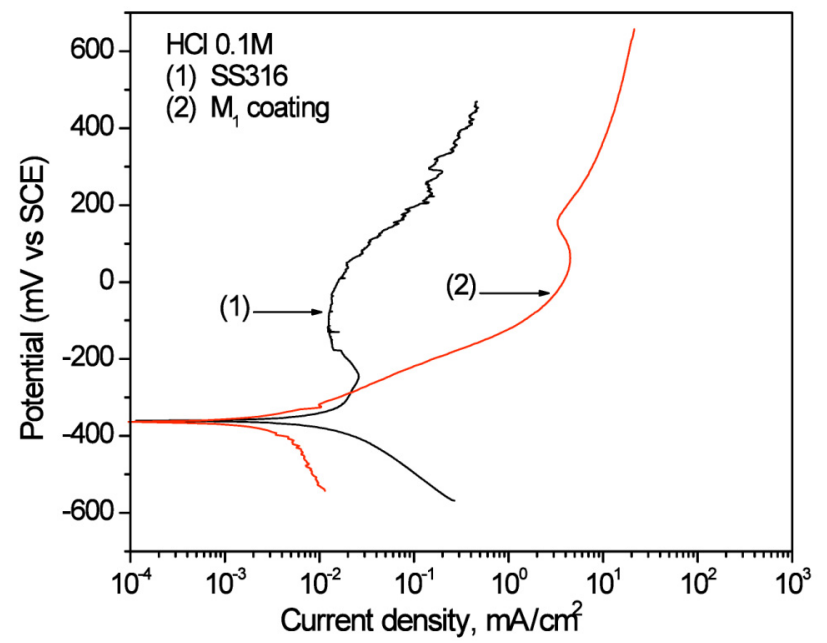

Fig. (5). Potentiodynamic polarization curves obtained in $0.1 \mathrm{M}$ $\mathrm{HCl}$ solution at room temperature for stainless steel 316 and coating systems.

Derived from the over-potential applied, anodic current density increases with some controlled rate up to this rate increases also; this may indicate preferential localized attack, principally occurred after the electric potential exceeded the breakdown potential. This localized attack, where electrochemical reaction at the interface happens freely, 
Table 2. Summary of the Electrochemical Parameters Measured from Polarization Results in the HCl Solutions

\begin{tabular}{|c|c|c|c|c|c|}
\hline Sample & Electrolyte & $\begin{array}{c}E_{\text {corr }} \\
(\mathrm{mV})\end{array}$ & $\begin{array}{c}i_{\text {corr }} \\
\left(\mathrm{mA} / \mathbf{c m}^{2}\right)\end{array}$ & $\begin{array}{c}B a \\
(\mathbf{m V})\end{array}$ & $\begin{array}{c}B c \\
(\mathrm{mV})\end{array}$ \\
\hline uncoated & \multirow{3}{*}{$1 \mathrm{M} \mathrm{HCl}$} & -465 & $2.77 \times 10^{-1}$ & 111 & 126 \\
\hline $\mathrm{M}_{1}$ & & -361 & $1.03 \times 10^{-2}$ & 053 & 255 \\
\hline $\mathrm{C}_{1}$ & & -427 & $3.12 \times 10^{-2}$ & 039 & 235 \\
\hline uncoated & \multirow{2}{*}{$0.1 \mathrm{M} \mathrm{HCl}$} & -358 & $1.51 \times 10^{-2}$ & 422 & 167 \\
\hline $\mathrm{M}_{1}$ & & -364 & $3.50 \times 10^{-3}$ & 99 & 343 \\
\hline
\end{tabular}

resulted in debonding, delaminating and lifting of the coating from the substrate, possibly due to hydrolysis reactions at the interface [36]. Additionally, the diffusion of the oxidant ions speeds up and the corrosion rate increases causing an accumulation of the corrosion products at the interface, promoting the formation of bulges and even leading to microcracks as it can be seen as an example in Fig. (6), before reported by Dianran et al. [37] also. As the corrosion products increase, the protective coating is lost by peeling of the film, such an example was the cause of the observed coating damage. Fractures of the ceramic coatings derived by the increasing of sweep over-potential initially grow from small cracking points or pitting in the coating. However, increasing higher potential promoted the cracking and peeling of the coating as shown in Fig. (6). More evident damage was observed in the $\mathrm{M}_{1}$ coating in $0.1 \mathrm{M}$ solution (Fig. 6b), where the corrosion mechanism was mainly controlled by activation (Fig. 3). However, the coating samples showed higher corrosion resistance described by the $E_{\text {corr }}$ and $i_{\text {corr }}$ values (Tables $\mathbf{1}$ and 2), as reported before [22, 23, 36].

At the beginning of an interaction in a corrosive environment, the ceramic coating keeps a barrier between the substrate and environment protecting it from corrosion. Micropores and microcracks that could be present in the ceramic film play an important role in the corrosion, which generate a particular stage, high or low weight losses. In Fig. (7) we propose a different corrosion mechanism at the interface between the sol-gel coating and the stainless steel substrate. The Schematic illustrate the possible corrosion mechanisms of coating/SS 316 interface into: a) $\mathrm{H}_{2} \mathrm{SO}_{4}$ and b) $\mathrm{HCl}$ solutions. The possible paths for the electrochemical reaction between the corrosive and metal ions at the coating/substrate interface affects in the formation of an oxide layer, which could grow passive layer to enhance the corrosion resistance. Cracking during drying is a rare condition but could occur when the gel has had insufficient ageing and strength [10]. After drying, the coatings were densified by heat treatment. During this step the residual stress grows until the point of generating some microcracks into the coating. Residual stress in the interface comes from the differential thermal expansion of both substrate and film coating. However, as soon as the corrosive medium penetrates through the layer and reaches the substrate, an electrochemical reaction takes place, causing an increase of current density. Fortunately, the evaluated coatings did not show such behaviour and the surface appearance obtained by SEM characterization did not present substantial density of those defects (Fig. 1). Similar behaviour has been attributed to the presence of the methyl groups of the hybrid coatings which generate a hydrophobic barrier that restricts the access of the aqueous electrolyte into the coating pores, improving the corrosion resistance of the coating material [24].

In this sense, the affinity of sulphuric acid for water is sufficiently strong that it will remove hydrogen and oxygen atoms from other compounds. In this way, when a material reaches an over-potential condition by the dynamic polarization (as in the present work), it promotes that corrosion to take place on the metallic surface by forced way. The diffusion through the corrosion products or coating barrier increases driven by over potential force which causes an increase in the ion concentration at the interface promoting the oxidation reaction of metal. In the $\mathrm{H}_{2} \mathrm{SO}_{4}$ solutions, the electrochemical reactions are: $\mathrm{H}_{2} \mathrm{SO}_{4}+\mathrm{H}_{2} \mathrm{O} \rightarrow \mathrm{H}_{3} \mathrm{O}^{+}+\mathrm{HSO}_{4}^{-}$, and then $\mathrm{HSO}_{4}^{-}+\mathrm{H}_{2} \mathrm{O} \rightarrow \mathrm{H}_{3} \mathrm{O}^{+}+\mathrm{SO}_{4}^{2-}$.

Then, $\mathrm{SO}_{4}^{2-}$ and $\mathrm{O}^{2-}$ ions diffusion (last from aerated solution) through metal/coating interface is driven by the over potential changes. In materials protected by ceramic coatings, this corrosion activity can promote the coating scaling by the corrosion products accumulation (schematized

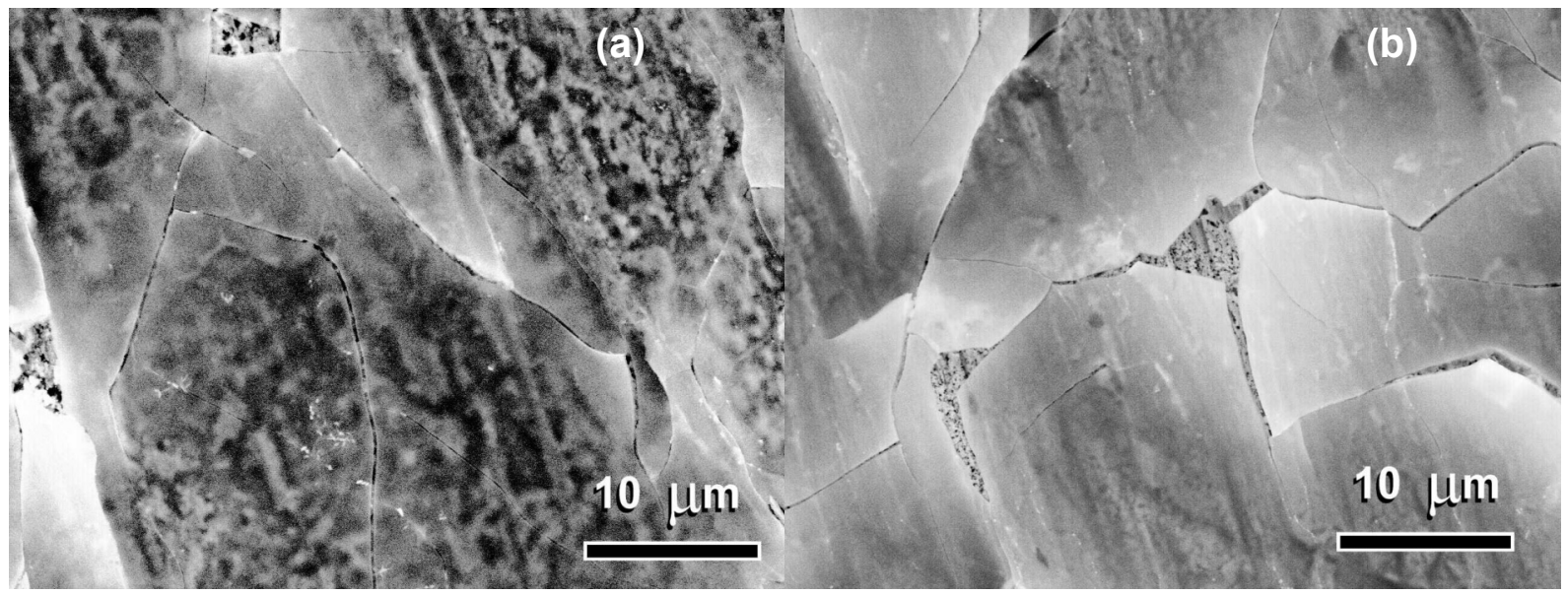

Fig. (6). SEM micrograph of the $\mathrm{M}_{1}$ coating potentiodynamic test in the $\mathrm{H}_{2} \mathrm{SO}_{4}$ solution with: (a) $1.0 \mathrm{M}$ and (b) $0.1 \mathrm{M}$ concentrations. The forced damage of coating was generated by the high potential increase in the anodic region. 
in Fig. 7a). As a result, formation of bulges and even leading to microcracks as it can be seen in Fig. (6), previously reported by Dianran et al. [37]. As the corrosion products increase, the protective coating is lost by peeling of the film, which might be the cause of the observed coating damage. Pure sulphuric acid reacts with most metals via a single displacement reaction to produce hydrogen gas and the metal sulphate, however, diluted $\mathrm{H}_{2} \mathrm{SO}_{4}$ attacks iron, (and many metals as: aluminium, zinc, manganese, magnesium and nickel). In this way, the general reaction with iron is: $\mathrm{Fe}(\mathrm{s})+$ $\mathrm{H}_{2} \mathrm{SO}_{4}$ (aqueous) $\rightarrow \mathrm{H}_{2}(\mathrm{~g})+\mathrm{FeSO}_{4}$; or electrochemical reaction: $\mathrm{Fe}^{2+}+\mathrm{SO}_{4}^{2-} \rightarrow \mathrm{FeSO}_{4}$. Additionally the $\mathrm{Cr}$ contents an $\mathrm{O}$, gives the oxidation and reduction of $\mathrm{Cr} \rightarrow$ $\mathrm{Cr}^{2+}+2 \mathrm{e}^{-} ; \mathrm{Cr}^{2+} \rightarrow \mathrm{Cr}^{3+}+\mathrm{e}^{-}$and $\mathrm{O}_{2}+2 \mathrm{e}^{-} \rightarrow 2 \mathrm{O}^{2-}$; then $2 \mathrm{Cr}^{3+}+3 \mathrm{O}^{2-} \rightarrow \mathrm{Cr}_{2} \mathrm{O}_{3}$ reaction occurs at the metal/coating interface.
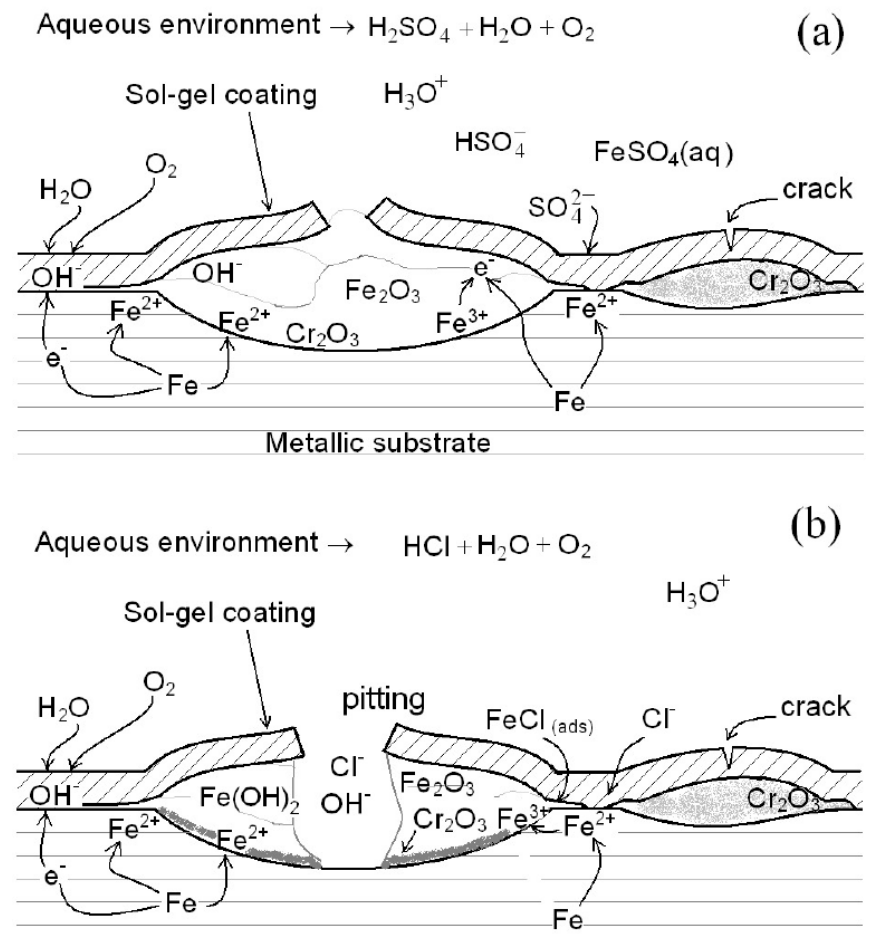

Metallic substrate

Fig. (7). Schematic illustrations of possible corrosion mechanisms (from SEM images in Fig. (6) of coating/SS 316 interface into: (a) $\mathrm{H}_{2} \mathrm{SO}_{4}$ and (b) $\mathrm{HCl}$ solutions.

In the $\mathrm{HCl}$ solutions, the electrochemical reaction is: $\mathrm{HCl}$ $+\mathrm{H}_{2} \mathrm{O} \rightarrow \mathrm{H}_{3} \mathrm{O}^{+}+\mathrm{Cl}^{-}$. If these solutions are aerated, the oxidizing ions are compounded by $\mathrm{Cl}^{-}$and $\mathrm{O}^{2-}$ ions, (Fig. 7b). The corrosion products are constituted by $\mathrm{Cl}$ and $\mathrm{Fe}$ in addition to the oxygen. These products grow easily and their structure is not protective, generating localized corrosion such pitting and crevice corrosion. The anodic metal dissolution reaction occurs principally by: oxidation of $\mathrm{Fe} \rightarrow$ $\mathrm{Fe}^{2+}+2 \mathrm{e}^{-}$then $\mathrm{Fe}^{2+}+2 \mathrm{Cl}^{-} \rightarrow \mathrm{FeCl}_{2}$; also $\mathrm{Fe}^{2+} \rightarrow \mathrm{Fe}^{3+}+$ $\mathrm{e}^{-}$; and $2 \mathrm{Fe}^{3+}+3 \mathrm{O}^{2-} \rightarrow \mathrm{Fe}_{2} \mathrm{O}_{3}$; also $2 \mathrm{Cr}^{3+}+3 \mathrm{O}^{2-} \rightarrow$ $\mathrm{Cr}_{2} \mathrm{O}_{3}$ happens. However, stainless steels in chloride solutions pitting corrosion, then, at the bottom of the pit, $2 \mathrm{Fe}$ $\rightarrow 2 \mathrm{Fe}^{2+}+4 \mathrm{e}^{-}$, is balanced by the cathodic reaction at the adjacent surface, $\mathrm{O}_{2}+2 \mathrm{H}_{2} \mathrm{O}+4 \mathrm{e}^{-} \rightarrow 4 \mathrm{OH}^{-}$. The increased concentration of $\mathrm{Fe}^{2+}$ within the pit results in the migration of chloride ions $\left(\mathrm{Cl}^{-}\right)$to maintain neutrality. The metal chloride formed, $\mathrm{FeCl}_{2}$, is hydrolyzed by $\mathrm{H}_{2} \mathrm{O}$, hydroxide and free acid, $\mathrm{FeCl}_{2}+2 \mathrm{H}_{2} \mathrm{O} \rightarrow \mathrm{Fe}(\mathrm{OH})_{2}+2 \mathrm{H}^{+}+2 \mathrm{Cl}^{-}$. This acid drops $\mathrm{pH}$ values at the bottom of the pit while the $\mathrm{pH}$ of the bulk remains neutral [38].

The kinds of corrosion products were attributed to the difference on corrosion reactions of the metal/coating interfaces in these solutions (Figs. 2-5). The reaction of substrate interface in $\mathrm{H}_{2} \mathrm{SO}_{4}$ and $\mathrm{HCl}$ solutions promotes the interaction of $\mathrm{Fe}$ and $\mathrm{Cr}$ with the oxidizers as $\mathrm{O}$, and $\mathrm{S}$, and $\mathrm{O}$ and $\mathrm{Cl}$ respectively, then the formation of a protective film on the metallic surface principally by the chromium oxide minimizing the corrosion rate by passivation and spreading of microcracks. The increase of exposed area to corrosion phenomena due to coating spilling causes the increase in current density occurred at high over-potential, and explain the increase in anodic current over some ranges of potential. Nevertheless, the coatings evaluated in the current work developed good corrosion resistance, showing passivation region implied that the sol-gel coatings indeed provided a physical barrier for blocking the electrochemical corrosion process [34].

\section{CONCLUSIONS}

Hybrid $\mathrm{C}_{1}$ and ceramic mix-oxide $\mathrm{M}_{1}$ sols were synthesized by a sol-gel process producing protective films with different properties and used to dip-coat "ormocers" coatings on SS 316. The protective properties in corrosion environments of both coating systems tested by the potentiodynamic technique suggest good corrosion resistance at OCP conditions. The $\mathrm{M}_{1}$ coatings prevent the corrosion resistance in the $\mathrm{H}_{2} \mathrm{SO}_{4}$ solutions by a mechanism limited or controlled by seudo-passivation, and presented a second passivation potential region in $0.1 \mathrm{M}$ solution. Also the $\mathrm{C}_{1}$ coating developed beneficial passivation behaviour in this solution concentration.

In the $\mathrm{HCl}$ solutions, both coatings improved corrosion resistance at the OCP region. In addition, the more positive $E_{\text {corr }}$ was obtained by $\mathrm{M}_{1}$ coating into $1 \mathrm{M} \mathrm{HCl}$ solution (around $100 \mathrm{mV}$ more positive than substrate), and this $E_{\text {corr }}$ became more negative as the solution concentration decrease at $0.1 \mathrm{M}$. However, the more important feature of the results was their electrochemical behaviour in the near $E_{\text {corr }}$ region, in which the coatings shown good response of corrosion resistance. Furthermore, the $i_{c o r r}$ values resulted to be smaller than $i_{\text {corr }}$ from the uncoated material.

The origin of the deterioration of the coatings was clearly revealed by the presence of microcracks which acts as connecting pathways for the corrosive environments. The different corrosion resistance shown by protective coatings in the corrosive media was related by the development of specific corrosion products. In $\mathrm{H}_{2} \mathrm{SO}_{4}$, chromium oxides grown into metal-coating interface, which developed the best behaviour as characteristic passivation curves, while chlorine solutions generated chlorine compounds into interface cause 
of bulge formations, lifting and spalling of protective coatings, thus same behaviour than uncoated material.

\section{ACKNOWLEDGEMENTS}

The authors acknowledge the technical help of $\mathrm{H}$. E. Esparza-Ponce, A. Rojas, G. Hernandez, C. Peza.

\section{REFERENCES}

[1] Dislich H, Hussmann E. Amorphous and crystalline dip coatings obtained from organometallic solutions - procedures, chemical processes and products. Thin Solids Films 1981; 77: 129-39.

[2] Dislich H. Sol-Gel Technology for Thin Films, Fibers, Preforms, Electronics and Specialty Shapes. In: Klein LC, Ed. Thin Films from the Sol-Gel Process. Park Ridge, NJ: Noyes Publications 1988; pp. 50-79.

[3] De Lima Neto P, Atik M, Avaca LA, Aegerter MA. Sol-gel coatings for chemical protection of stainless steel. J Sol-Gel Sci Technol 1994; 2: 529-34.

[4] Brinker CJ, Hurd AJ, Ward KJ. Fundamentals of sol-gel thin film formation. In: Mackenzie JD, Ulrich DR, Eds. Ultrastructure Processing of Advanced Ceramics. New York: John Wiley and Sons 1988; pp. 223-53.

[5] Brinker CJ, Hurd AJ, Frye GC, Ward KJ, Ahsley CS. Sol-gel thinfilm formation. J Non-Cryst Solids 1990; 121: 294-302.

[6] Judeinstein P, Sanchez C. Hybrid organic-inorganic materials: a land of multi-disciplinarity. J Mater Chem 1996; 6: 511-25.

[7] Almaral-Sanchez JL, Rubio E, Mendoza-Galvan A, Ramirez-Bon R. Red colored transparent PMMA-SiO ${ }_{2}$ hybrid films. J Phys Chem Solids 2005; 66: 1660-7.

[8] Park JS, Mackenzie JD. Microstructure effects in multidipped tin oxide-films. J Am Ceram Soc 1995; 78: 2669-72.

[9] Huang HH, Orler B, Wilkes GL. Structure-property behavior of new hybrid materials incorporating oligomeric species into sol-gel glasses. 3. Effect of acid content, tetraethoxysilane content, and molecular weight of poly(dimethylsiloxane). Macromolecules 1987; 20: 1322-30.

[10] Brinker CJ, Scherer GW, Eds. Sol-gel science. The physics and chemistry of sol-gel processing. Boston: Academic Press 1990.

[11] Brennan AB, Wang B, Rodrigues DE, Wilkes GL. Structureproperty behavior of novel Ti/poly(tetramethylene oxide) (PTMO) and $\mathrm{Zr} / \mathrm{PTMO}$ hybrid Ceramer materials prepared by the sol gel method. J Inorg Organomet Polym 1991; 2: 167-87.

[12] Glaser RH, Wilkes GL. Structure property behavior of polydimethylsiloxane and poly(tetramethylene oxide) modified teos based sol-gel materials. 5. Effect of titaniumisopropoxide incorporation. Polym Bull 1988; 29: 51-7.

[13] Surivet F, Lam TM, Pascault JP. Control synthesis of isocyanate and alkoxy-silane terminated macromers. J Polym Sci Pol Chem 1991; 29: 1977-86.

[14] Surivet F, Lam TM, Pascault JP, Pham OT. Organic-inorganic hybrid materials. 1. Hydrolysis and condensation mechanisms involved in alkoxysilane-terminated macromonomers. Macromolecules 1992; 25: 4309-20.

[15] Surivet F, Lam TM, Pascault JP, Mai C. Organic-inorganic hybrid materials. 2. Compared structures of polydimethylsiloxane and hydrogenated polybutadiene based ceramers. Macromolecules 1992; 25: 5742-51.

[16] Wang S, Ahmad Z, Mark JE. Polyimide-silica hybrid materials modified by incorporation of an organically substituted alkoxysilane. Chem Mater 1994; 6: 943-6.
[17] Iyoku $\mathrm{Y}$, Kakimoto $\mathrm{M}$, Imai $\mathrm{Y}$. The preparation of poly(methylsilsesquioxane) network-polyimide hybrid materials by the sol-gel process and their properties. High Perform Polym 1994; 6: 43-52.

[18] Tuman SJ, Soucek MD. Novel inorganic organic coatings based on linseed oil and sunflower oil with sol-gel precursors. J Coating Technol 1996; 68: 73-81.

[19] Wold CR, Soucek MD. Mixed metal oxide inorganic/organic coatings. J Coating Technol 1998, 70: 43-51.

[20] Atik M, De Lima Neto P, Avaca LA, Aegerter MA, Zarzycki J. Protection of $316 \mathrm{~L}$ stainless-steel against corrosion by $\mathrm{SiO}_{2}$ coatings. J Mater Sci Lett 1994; 13: 1081-5.

[21] Simoes M, Assis BGO, Avaca LA. Some properties of protective sol-gel glass coatings on sintered stainless steels. J Non-Cryst Solids 2000; 273: 159-63.

[22] Carbajal G, Martínez-Villafane A, Gonzalez-Rodriguez JG, Castano VM. Corrosion-resistant coatings: a nanotechnology approach. Anti-Corrosion Met Mater 2001; 48: 241-4.

[23] Carbajal de La Torre G, Mendoza RN, Espinosa-Medina MA, Martinez-Villafane A, Gonzalez-Rodriguez JG, Castano VM Corrosion protection of 1008 carbon steel by hybrid coatings. Br Corrosion J 2002; 37: 293-7.

[24] Amato LE, López DA, Galliano PG, Cere SM. Electrochemical characterization of sol-gel hybrid coatings in cobalt-based alloys for orthopaedic implants. Mater Lett 2005; 59: 2026-31.

[25] Giacomelli FC, Giacomelli C, De Oliveira AG, Spinelli A. Effect of electrolytic $\mathrm{ZrO}_{2}$ coatings on the breakdown potential of NiTi wires used as endovascular implants. Mater Lett 2005; 59: 754-8.

[26] Balamurugan A, Kannan S, Rajeswari S. Structural and electrochemical behaviour of sol-gel zirconia films on 316L stainless-steel in simulated body fluid environment. Mater Lett 2003; 57: 4202-5.

[27] Hirano S, Kato K. Formation of $\mathrm{LiNBO}_{3}$ films by hydrolysis of metal alkoxides. J Non-Cryst Solids 1988; 100: 538-41.

[28] Schroeder H. Oxide layers deposited from organic solutions. Phys Thin Films 1969; 5: 87-141.

[29] Yano S, Iwata K, Kurita K. Physical properties and structure of organic-inorganic hybrid materials produced by sol-gel process. Mater Sci Eng C Biol Sci 1998; 6: 75-90.

[30] Chenier JP. Survey of industrial chemistry. New York: John Wiley \& Sons 1987.

[31] Gallardo J, Duran A, Garcia I, Celis JL, Arenas MA, Conde A. Effect of sintering temperature on the corrosion and wear behavior of protective SiO2-based sol-gel coatings. J Sol-Gel Sci Technol 2003; 27: 175-83.

[32] ASTM A262-02a (Re-approved 2008), "Standard Practices for Detecting Susceptibility to Intergranular Attack in Austenitic Stainless Steels", ASTM International, USA 2008.

[33] Molera Sola P. Metales Resistentes a la corrosión. Editorial Marcombo, Barcelona SA, 1990.

[34] Chou TP, Chandrasekaran C, Cao GZ. Sol-gel-derived hybrid coatings for corrosion protection. J Sol-Gel Sci Technol 2003; 26: $321-7$.

[35] Fontana GM. Corrosion engineering, New York: McGraw-Hill 1986.

[36] Chan CM, Cao GZ, Fong H, Sarikaya M, Robinson T, Nelson L. Nanoindentation and adhesion of sol-gel-derived hard coatings on polyester. J Mater Res 2000; 15: 148-54.

[37] Dianran $Y$, Jining $H$, Jianjun W, Wanqi Q, Jing $M$. The corrosion behaviour of a plasma spraying $\mathrm{Al}_{2} \mathrm{O}_{3}$ ceramic coating in dilute HC1 solution. Surf Coating Technol 1997; 89: 191-5.

[38] Sedriks AJ. Corrosion of stainless steels. New York: John Wiley \& Sons 1979. 